University of Nebraska - Lincoln

DigitalCommons@University of Nebraska - Lincoln

\title{
Taxonomy of Janetiella thymi (Kieffer) (Diptera: Cecidomyiidae) and of the Species Formerly in Janetiella That Feed on Vitis (Vitaceae)
}

\author{
Raymond Gagne \\ Systematic Entomology Laboratory, PSI, Agricultural Research Service, USDA, c/o U. S. National Museum \\ NHB 168, P.O. Box 37012, Washington, DC 20013-7012, USA, raymond.gagne@ars.usda.gov
}

Follow this and additional works at: https://digitalcommons.unl.edu/systentomologyusda

Part of the Entomology Commons

Gagne, Raymond, "Taxonomy of Janetiella thymi (Kieffer) (Diptera: Cecidomyiidae) and of the Species Formerly in Janetiella That Feed on Vitis (Vitaceae)" (2009). USDA Systematic Entomology Laboratory. 21.

https://digitalcommons.unl.edu/systentomologyusda/21

This Article is brought to you for free and open access by the Entomology Collections, Miscellaneous at DigitalCommons@University of Nebraska - Lincoln. It has been accepted for inclusion in USDA Systematic Entomology Laboratory by an authorized administrator of DigitalCommons@University of Nebraska - Lincoln. 


\title{
TAXONOMY OF JANETIELLA THYMI (KIEFFER) (DIPTERA: CECIDOMYIIDAE) AND OF THE SPECIES FORMERLY IN JANETIELLA THAT FEED ON VITIS (VITACEAE)
}

\author{
RAyMond J. GAGnÉ
}

Systematic Entomology Laboratory, PSI, Agricultural Research Service, U.S. Department of Agriculture, c/o Smithsonian Institution MRC-168, P.O. Box 37012, Washington, DC 20013-7012, U.S.A. (e-mail: Raymond.Gagne@ars.usda.gov)

Abstract.-The poorly known European species Janetiella thymi (Kieffer), type species of Janetiella Kieffer (Diptera: Cecidomyiidae), is redescribed. Gall makers on grape that were formerly placed in Janetiella are shown to be distinct from that genus and transferred to Vitisiella Fedotova \& Kovalev, a genus recently erected for a species on grape in Siberia. Among the distinguishing traits of Vitisiella, more fully characterized here than previously, are the closed costal vein at its juncture with $\mathrm{R}_{5}$, the deeply divided male hypoproct, and the conspicuous dorsolateral sclerites of the ovipositor. Janetiella brevicauda Felt, also redescribed, and Cecidomyia oenephila Haimhoffen, both previously placed in Janetiella, are newly combined with Vitisiella.

Key Words: Holarctic, gall midges, grape, Dasineurini

Janetiella Kieffer currently includes 28 species (Gagné 2004). This genus has traditionally accommodated species that share similarities with Dasineura Rondani but differ mainly in that the tarsal claws are simple instead of toothed. As for any broadly defined genus, Janetiella shows considerable anatomical and host diversity (Gagné 1989, 2004). While constructing a new key to genera of Nearctic gall midges, I have found it necessary to reexamine the 13 Nearctic species of Janetiella and place some of them elsewhere (e.g., Gagné 2009). One apparently monophyletic group of species associated with leaf galls on grape is exemplified here by Janetiella brevicauda Felt. Comparing this group with the European Janetiella thymi Kieffer, type species of Janetiella, was hindered by the

* Accepted by David R. Smith fact that no redescription of that species has appeared since the original description (Kieffer 1888), one that was evidently based on dry, uncleared specimens. Details such as the number of palpal segments, effectively used to discriminate among genera of gall midges, were omitted. Kieffer (1898) subsequently implied and later stated (Kieffer 1913) that species of Janetiella have four-segmented palpi, but specimens of $J$. thymi available to me from Sweden have only three segments, unlike all other species of Janetiella presently assigned to the genus. The occasion is taken here to redescribe and illustrate $J$. thymi for future reference.

Janetiella brevicauda is only one of several closely related Nearctic species, described and undescribed (R. Gagné pers. obs.), that form a variety of circular or blister galls on grape leaves (Gagné 1989) and that share similar derived 
features with the Palearctic Janetiella oenephila (Haimhoffen). Fedotova and Kovalev (2003) recently described another grape-infesting species from Siberia and proposed for it a new genus, Vitisiella Fedotova \& Kovalev. That genus is redescribed here in more detail than originally and is shown to encompass the other known species of Janetiella from grape leaves.

Also commented upon here is a character that has been little noted previously. This is a pair of dorsolateral, elongate, dermal sclerites that span the length of the female ninth abdominal segment and presumably serve to stiffen the ovipositor. They are usually fine and subtle and not always apparent on cleared specimens but are especially prominent on $J$. brevicauda (Fig. 21). In that species and its relatives, the sclerites are broadest anteriorly and end posteriorly in a short elbow at the base of the cerci (Fig. 22). Similar but much less conspicuous sclerites can be seen on many other female Cecidomyiinae that have protrusible ovipositors. I have now seen them in various other taxa, including $J$. thymi (Fig. 10), Dasineura mali (Kieffer), Lasioptera solidaginis (Osten Sacken), and Contarinia pyrivora (Riley). Solinas (1965) illustrated them without comment for Contarinia medicaginis Kieffer, and they are recognizable in sketches of various dasineurine species in Sylvén and Tastás-Duque (1993). Possibly the unified "dorsal sclerite" of Caryomyia (Gagné in press) is homologous with the separate sclerites. Roskam (1977) illustrated them in detail for Semudobia skuhravae Roskam and labelled them as part of the genital furca but to which they have no connection. The sclerites are definitely dermal structures, as they are visible on uncleared specimens, and they are dorsal rather than ventral. The presence of these sclerites may serve little diagnostic purpose except when more prominently developed as they are in species of Vitisiella and Semudobia Kieffer.

\section{Materials And Methods}

Terminology for adult morphology in this paper follows usage in McAlpine et al. (1981) and for larval morphology that in Gagné (1989).

\section{Results AND Discussion}

\section{Janetiella thymi (Kieffer)}

Cecidomyia thymi Kieffer 1888: 100.

Janetiella thymi: Kieffer 1898: 23; Coquillett 1910: 556, designated as type species; Kieffer 1913: 59, in list spp. following generalized generic description; Rübsaamen and Hedicke 1938: 296 (key), pl. XXVII, figs. 15-17 showing galls and larval sternal spatula.

Adult.-Head: Eye facets circular, nearly contiguous on ventral $2 / 3$ of eye, 1 to $11 / 2$ facets diameter apart on dorsal third of eye, eyes separated at vertex by twice eye facet diameter. Antenna with 12 flagellomeres in both sexes, first and second connate, distal 2 or 3 in females more or less fused; at least first and second flagellomeres of male with necks about 1/2 length of node (Fig. 1); flagellomeres of female with necks no more than 1/10 length of node (Fig. 2). Frons with 8-10 setae and scales per side. Labellum hemisperical in frontal view, with several setae. Palpus (Fig. 3) 3segmented, first segment as long as wide, second and third each twice as long as preceding.

Thorax: Scutum with sparse setae laterally on anterior half and 2 longitudinal dorsocentral rows, latter set for much of its length made up of single row of setae mixed with scales anteriorly. Scutellum with group of setae on each side. Anepisternum with few scales dorsally; anepimeron with vertical row of 58 setae; pleura otherwise bare. Wing (Fig. 4): $\mathrm{C}$ broken at $\mathrm{R}_{5} ; \mathrm{R}_{5}$ reaching $\mathrm{C}$ slightly anterior to wing apex; $M$ not apparent; $\mathrm{Cu}$ forked. Acropod (Figs. 56): tarsal claws untoothed; empodia 

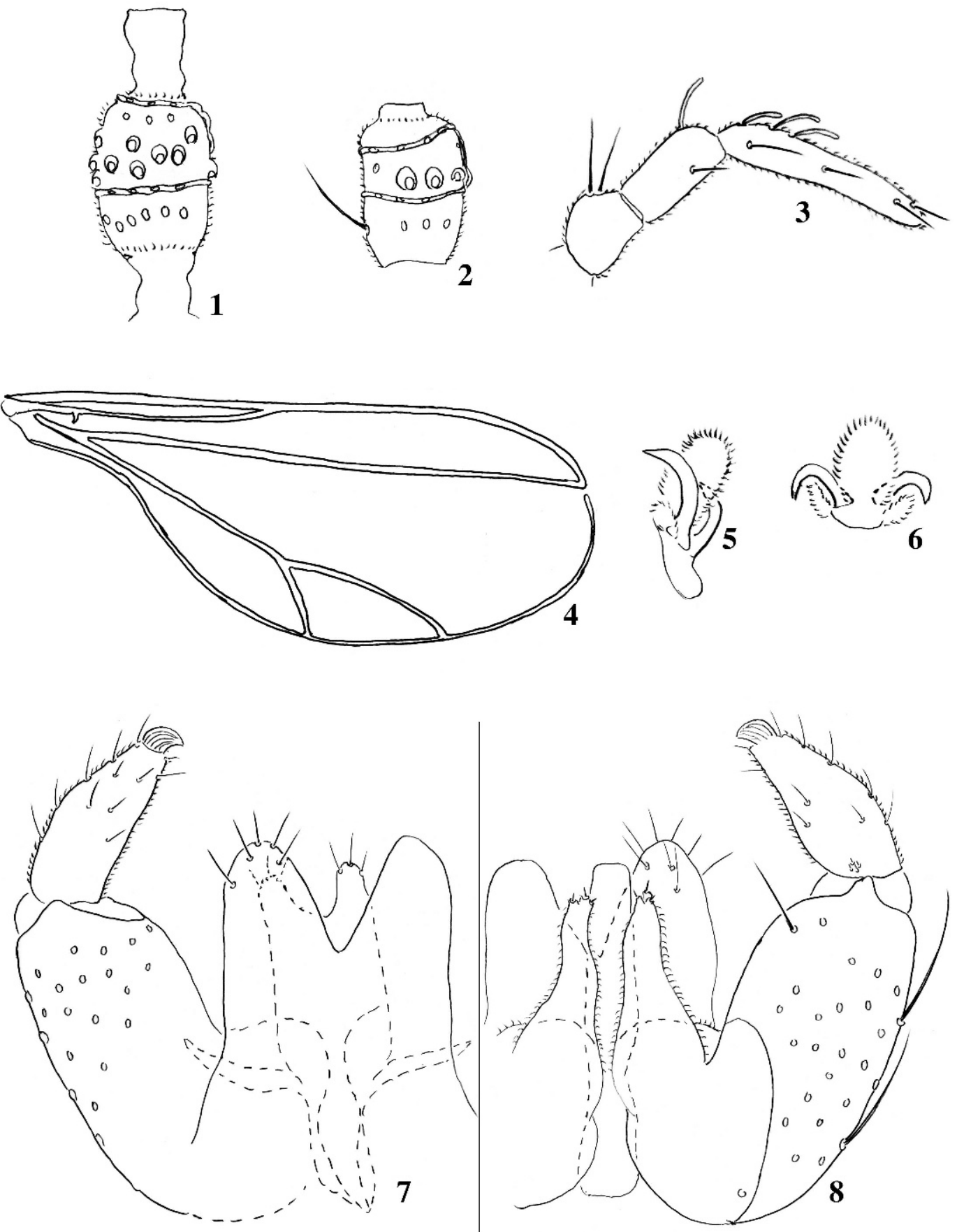

Figs. 1-8. Janetiella thymi. 1, Male second flagellomere (ventral). 2, Female third flagellomere (ventral). 3, Palpus. 4, Wing. 5, Acropod (lateral). 6, Acropod (ventral). 7, Male terminalia, one gonopod removed (dorsal). 8, Male terminalia, one gonopod removed (ventral). 
appreciably longer than claws; pulvilli less than $1 / 3$ as long as claws.

Male abdomen: First through sixth tergites with posterior margins wider than anterior, sixth tergite partially divided anteromesally, each tergite with single row of posterior setae, few scattered scales, and anterior pair of trichoid sensilla; seventh tergite (Fig. 13) sclerotized only anteriorly and laterally, with 1 seta on each posterolateral corner and pair of anterior trichoid sensilla; eighth tergite evident as 2 separate, short sclerites with anterior pair of trichoid sensilla the only vestiture. Second through seventh sternites rectangular with single row of posterior setae, scattered setae at midlength, and anterior pair of closely set trichoid sensilla, each sternite with unpigmented area between posterior and medial setae; eighth sternite shorter than seventh and completely pigmented, vestiture similar except anterior pair of trichoid sensilla not apparent. Terminalia (Figs. 7-8): cercus ellipsoid, setose dorsally and ventrally on apical third; hypoproct bilobed with 3 setae near apex of each lobe; gonostylus conical, widest near base, tapering gradually to curved apical tooth, completely setulose; mesobasal lobe of gonocoxite composed of short, spheroid dorsobasal lobe and elongate, tapered ventral arm nearly as long and closely juxtaposed to aedeagus, setulose except at short-setose apex; aedeagus evenly cylindrical, straight, blunt at apex.

Female abdomen: First through sixth tergites (Fig. 9) generally as in male except sixth appreciably narrower than fifth; seventh less than $1 / 2$ width of sixth and as long, with single row of posterior setae and anterior pair of trichoid sensilla; eighth tergite divided into 2 separate elongate tergites, longer than seventh tergite, each with 2-3 setae posteriorly and 1 trichoid sensilla anteriorly. Second to sixth sternites as for male; seventh sternite entire, with single row of posterior setae, scattered setae laterally, and anterior pair of closely set trichoid sensilla. Ovipositor (Figs. 9-12) moderately long, protrusible, ninth segment about $3 \times$ length of seventh tergite, with 2 thin dorsolateral sclerites along its length; cerci fused, ovoid, moderately dorsoventrally flattened, setulose and setose, about 10 setae on distal third peglike; hypoproct with 2 distal setae.

Full-grown larva.-As illustrated in Rübsaamen and Hedicke (1938), spatula unremarkable for a dasineurine, with moderately long shaft and two rounded anterior lobes, the concavity between the lobes of same shape as the lobes.

Specimens examined.-The adult description is based on a series of two males and six females reared from Thymus serpyllum L. collected on a Helianthemum heath at Strandtorp, Öland, Sweden, VI11-1977, by E. Sylvén, and reared VI-27 to 29-1977. Kieffer's syntypes of this species can be presumed lost (Gagné 1994). A neotype designation is desirable, but I would prefer to wait until specimens of at least one more collection in Europe can be made and compared with the description above to be absolutely certain that the specimens I have examined are identified correctly.

Remarks._Kieffer (1888) recorded this species from buds of both Thymus serpyllum and Thymus chamaedrys Fries (Lamiaceae) in northeastern France. His description of the adults contains little more than color and other surface characters. He also described the larva in general terms. Although Kieffer (1898) subsequently placed Janetiella with other genera that have four-segmented palpi and later (Kieffer 1913) listed four-segmented palpi as one generic character, the specimens from Sweden that I have studied have three-segmented palpi. It is not certain that Kieffer actually saw four-segmented palpi on $J$. thymi, and nowhere else has it been specifically stated that this particular 

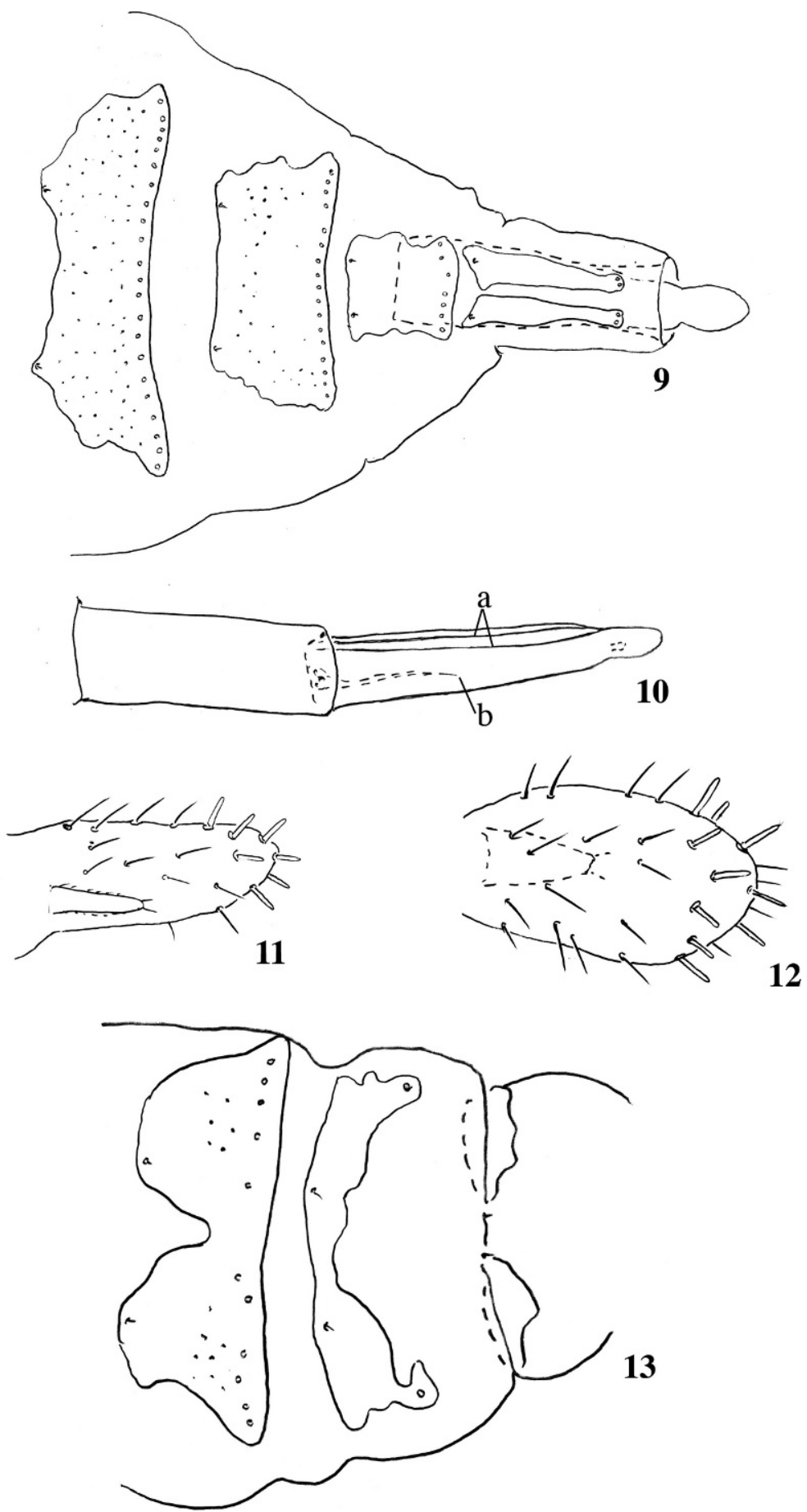

Figs. 9-13. Janetiella thymi. 9, Female abdomen, sixth tergite to end (dorsal). 10, Ovipositor (dorsolateral): a, dorsal pair of sclerites on ninth segment; b, genital furca. 11, Fused cerci and hypoproct (ventrolateral). 12, Fused cerci and hypoproct (dorsal). 13, Male abdomen, sixth through eighth tergites (dorsal). 
species has four, but all keys to the genus since then, including Felt (1915), Rübsaamen and Hedicke (1938), Gagné (1981), and Skuhravá (1997), key Janetiella as if all included species have four-segmented palpi. A four-segmented palpus evidently fits all species of Janetiella except the type species. The future will show whether the difference is important in this case. The number of palpal segments can be a useful character when static, but variation can occur in the number of palpal segments among species in a genus (e.g., Caryomyia (Gagné 2008)) and even on the same specimen (e.g., Asteromyia (Gagné 1968)). The most prominent characters of $J$. thymi that should serve to differentiate the genus from other Dasineurini are as follows:

Antenna with 12 flagellomeres. Costa and $\mathrm{R}_{5}$ joined anterior to wing apex; $\mathrm{C}$ broken beyond juncture with $\mathrm{R}_{5}$. Tarsal claws without basal teeth; empodia slightly longer than claws; pulvilli less than $1 / 3$ length of claws. Abdominal tergites with no more than single posterior row of setae and no lateral setae. Male eighth abdominal tergite considerably reduced in size and setation. Gonostylus conical, tapering to apical tooth, completely setulose; hypoproct moderately divided; aedeagus cylindrical and straight. Female seventh abdominal tergite less than $1 / 2$ width of sixth; eighth tergite divided into two discrete elongate sclerites; ovipositor protrusible, about $3 \times$ length of seventh tergite, pair of ninth segment dorsolateral sclerites narrow, inconspicuous; cerci fused, ovoid, widest at midlength with about 10 peglike setae on distal half. The larval spatula, as illustrated in Rübsaamen and Hedicke (1938), has two elliptical apical lobes separated by concavity mirroring lobes in shape and extent.

\section{Vitisiella Fedotova \& Kovalev}

Vitisiella Fedotova and Kovalev 2003: 25. Type species, Vitisiella vesicula Fedotova \& Kovalev (orig. des.).
Diagnosis.-Antenna with 13-14 flagellomeres in both sexes. $\mathrm{C}$ and $\mathrm{R}_{5}$ joined anterior to wing apex; $\mathrm{C}$ unbroken beyond juncture with $\mathrm{R}_{5}$; $\mathrm{M}$ not apparent; $\mathrm{Cu}$ forked. Tarsal claws without basal teeth; empodia as long as claws; pulvilli less than $1 / 3$ length of claws. Abdominal tergites with no more than single posterior row of setae and no lateral setae. Gonostylus widest at base, narrowed beyond, setulose basolaterally, lined with ridges elsewhere; hypoproct deeply divided; aedeagus longer than subtending gonocoxal lobes but shorter than gonocoxites, dorsally recurved apically. Female seventh abdominal tergite subequal in size to sixth; eighth tergite quadrate, undivided, much narrower than seventh; ovipositor protrusible, elongate, pair of ninth segment dorsolateral sclerites wide, conspicuous; cerci fused, cylindrical, rounded at apex, with about 10 peglike setae on distal half. Larval spatula with 2 triangular apical lobes. Eighth abdominal segment with single pair of ventral papillae instead of usual 2 pairs for Lasiopteridi. Terminal larval segment with 6 ( $V$. oenephila) or 8 ( $V$. brevicauda) setose papillae placed farther ventrad than usual so that 2 or 4 of them, respectively, are alongside anus.

The most prominent of the features that separate Vitisiella from Janetiella thymi are the closed costa at its juncture with R5, the deeply divided male hypoproct and dorsally recurved aedeagus, the conspicuous dorsolateral sclerites of the ovipositor, the single pair of ventral papillae on the larval eighth segment and the 1-2 pairs of terminal setae that stand next to the anus. All of these traits are presumably derived.

This diagnosis is based on the redescription of $V$. brevicauda that follows, a series of specimens of $V$. oenephila from Europe, and the description of $V$. vesicula in Fedotova and Kovalev (2003). The following three species, all feeding on grape, belong to Vitisiella. 


\section{Vitisiella brevicauda (Felt),} new combination

[Cecidomyia] vitis tomatos Riley 1873: 117. Invalid, a polynomial.

Janetiella brevicauda Felt 1908: 372 (description in key); Felt 1915: 224 (formal description).

Adult.-Head: Eye facets circular, contiguous on ventral $2 / 3$ and dorsal $1 / 4$ of eye, 1 to $11 / 2$ facets diameter apart on dorsal third, eyes separated at vertex by about $1 / 2$ eye facet diameter. Antenna with 13-14 flagellomeres, first and second connate, distal two fused; male flagellomeres (Fig. 15) with short necks, about 1/4 length of nodes; female flagellomeres with necks about 1/10 length of nodes. Frons with $12-15$ setae and as many scales per side. Labella hemisperical in frontal view, with several setae. Palpus 4-segmented, first slightly longer than wide, second slightly narrower and about twice length of first, third and fourth narrower than second and each about twice as long as second.

Thorax: Scutum with setae and scales laterally and 2 wide rows of setae mixed with scales dorsocentrally. Scutellum with group of setae and scales on each side. Anepisternum with a few setae and scales dorsally; anepimeron with vertical row of 20-26 setae; pleura otherwise bare. Wing (Fig. 16): $\mathrm{C}$ unbroken at juncture with $\mathrm{R}_{5}$; $\mathrm{R}_{5}$ reaching $\mathrm{C}$ slightly anterior to wing apex; $\mathrm{M}$ not apparent; $\mathrm{Cu}$ forked. Acropod (Fig. 14): tarsal claws without basal tooth; empodia as long as claws; pulvilli less than $1 / 3$ length of claws.

Male abdomen: First through sixth tergites rectangular, evenly sclerotized, each with single row of posterior setae, 0 lateral setae, scales covering tergites, and anterior pair of trichoid sensilla; seventh tergite (Fig. 17) narrower, with several setae on each posterolateral corner, a few scattered scales, and pair of anterior trichoid sensilla; eighth tergite much smaller than seventh, with anterior pair of trichoid sensilla the only vestiture. Second through seventh sternites rectangular, with mostly single row of posterior setae, scattered setae at midlength, and closely set anterior pair of trichoid sensilla, each sternite with unpigmented area between posterior and medial setae; eighth sternite smaller, with similar vestiture except anterior pair of trichoid sensilla set anterior to sclerite. Terminalia (Figs. 18-20): cercus elliptical, setose apically on dorsum and on distal half of venter; hypoproct deeply bilobed, lobes narrow, each with 3 setae distally; gonostylus broad on basal half, tapered beyond, setulae covering most of venter but only laterobasal part of dorsum, remainder of dorsal surface ridged; mesobasal lobe of gonocoxite composed of short, spheroid dorsal portion and elongate ventral arm gradually narrowing from base to apex, shorter than and closely juxtaposed to aedeagus, completely setulose with several apical setae set on pegs; aedeagus shorter than gonocoxite, apex slightly recurved dorsally.

Female abdomen (Figs. 21-22): First through sixth tergites as in male except sixth appreciably narrower than fifth; seventh less than $1 / 2$ width of sixth but as long, with mostly single row of posterior setae and anterior pair of trichoid sensilla; eighth tergite entire, slightly longer than wide, as long as seventh tergite, with anterior pair of trichoid sensilla and row of short setae posteriad of sclerite. Second to sixth sternites as for male; seventh sternite entire, with single row of posterior setae, scattered setae laterally, and anterior pair of trichoid sensilla. Ovipositor moderately long, protrusible, ninth segment about $3 \times$ as long as seventh tergite, with 2 prominent dorsolateral sclerites along length; cerci fused, cylindrical, setulose and setose, several setae on distal $1 / 3$ peglike; hypoproct with 2 apical setae.

Larva.-Spatula (Fig. 23) with 2 triangular anterior lobes, space between 

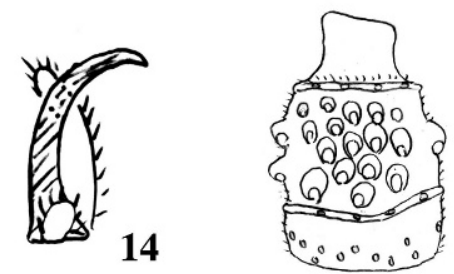

15
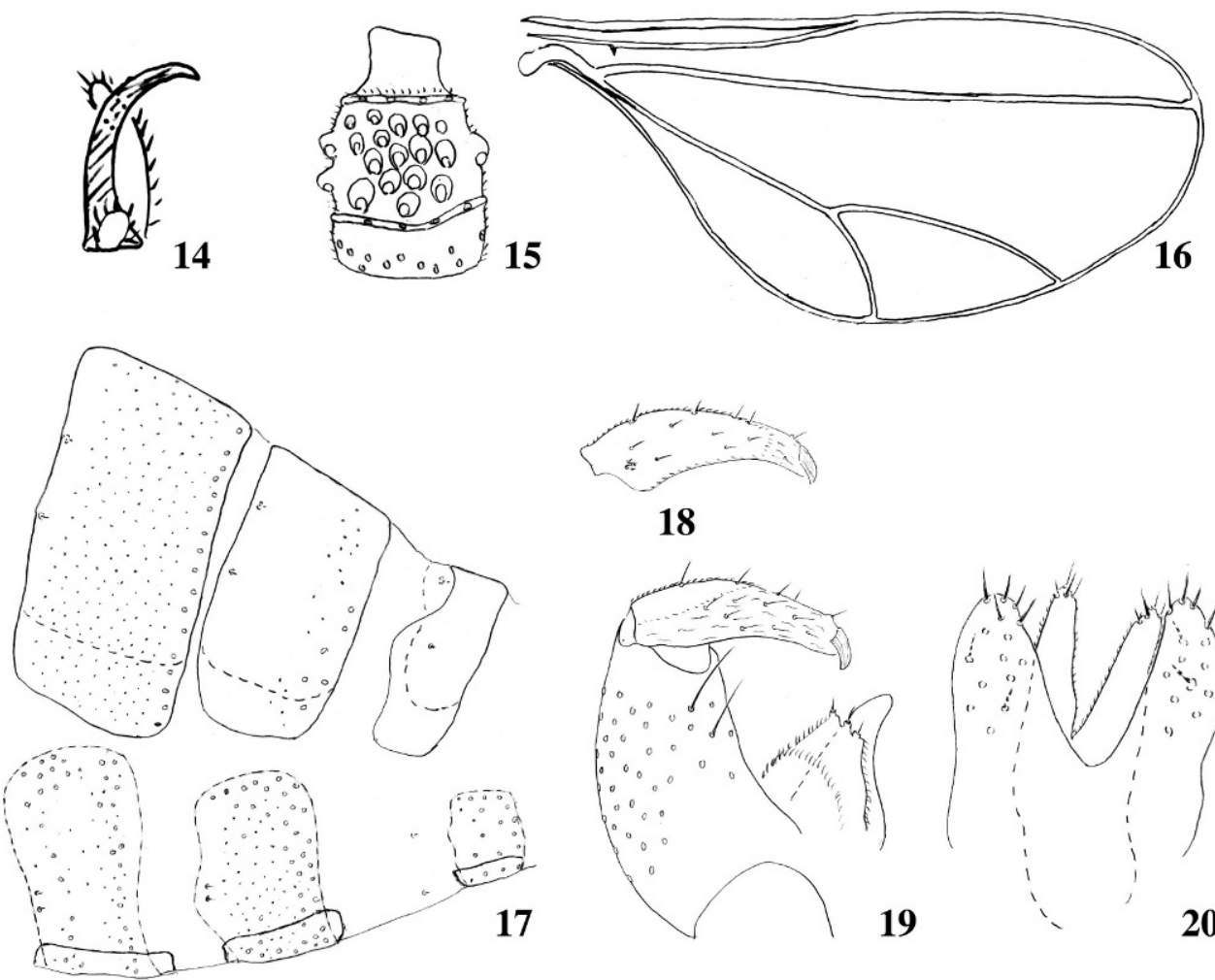

18

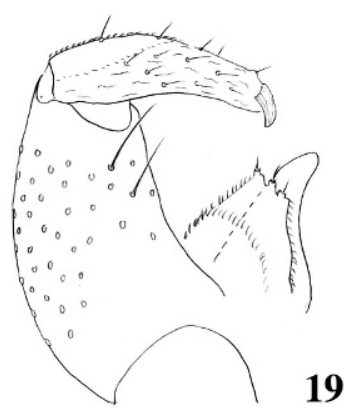

19

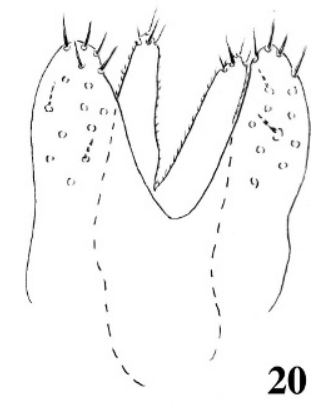

20
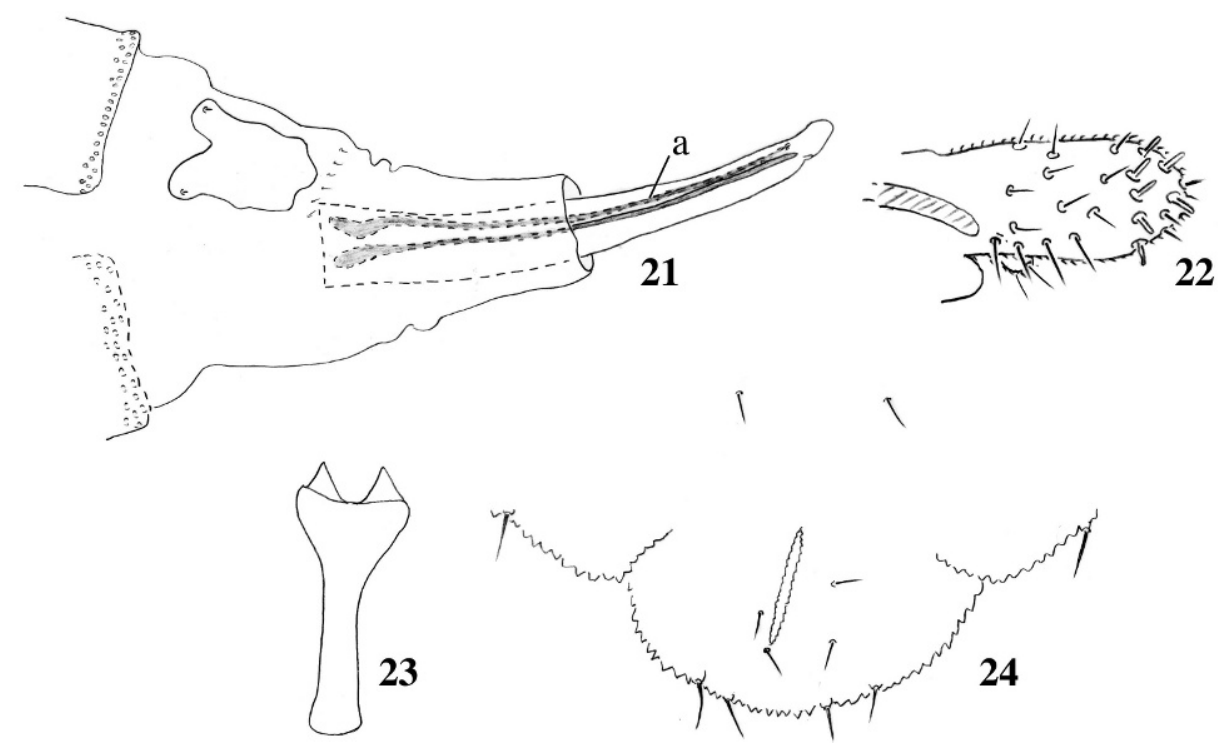

Figs. 14-24. Vitisiella brevicauda. 14, Acropod (lateral). 15, Male third flagellomere (ventral). 16, Wing. 17, Male sixth through eighth segments (dorsolateral). 18, Gonostylus (ventral). 19, Gonopod and aedeagus (dorsolateral). 20, Male cerci and hypoproct (dorsal). 21, Female seventh tergite to end (dorsolateral): a, lateral sclerite of ninth segment. 22, Detail of female fused cerci and hypoproct (dorsolateral). 23, Larval spatula. 24, Larval eighth and terminal abdominal segments (ventral). 
concave, and long shaft. Integument entirely verrucose. Papillae as for basic pattern of Lasiopteridi (Gagné 1994) except only 2 papillae instead of 4 present on eighth abdominal segment and 8 terminal papillae present but 4 situated ventrally to flank anus (Fig. 24).

Remarks.-This species is responsible for bright red, globular leaf and tendril galls of grapes in eastern North America (Gagné 1989) and probably beyond. Larvae collected in New Mexico agree with the description and are tentatively included under this species.

Specimens examined.-The description is based on the type series, a male and a female, from Missouri, and additionally the following series: Florida, Sebring, III3-1991, R.J. Gagné, larvae, + ; Maryland, Beltsville, V-1980, J.M. McGrew, larvae; Maryland, Long Beach, VI-4-1983, M.B. Stoetzel, larvae, 2 ๙ , 8 क; Maryland, Silver Spring, VI-21-1982, RJG, larvae; New Mexico, Carlsbad, V-21-1989, RJG, larvae; New York, Poughkeepsie, VII1949, R.B. Johnson, 4 ㅇ ; North Carolina, nr Jacksonville, V-9-1978, K. Corrette, 2 今, 3 오.

\section{Vitisiella oenephila (Haimhoffen), new combination}

Cecidomyia oenephila Haimhoffen 1875: 809

Janetiella oenephila: Kieffer 1913: 58 (as oenophila); Kovalev 1967: 105 (redescription).

This species has been recorded from Europe, the Middle East, and far-eastern Russia. It forms a round or oval gall, extending to both sides of the leaf, shiny on the upper surface and hairy on the lower (Haimhoffen 1875, Barnes 1948, Kovalev 1967). Specimens I have seen from such galls collected in Turkey differ little from $V$. brevicauda. Kovalev (1967) redescribed and illustrated the male, female, and larva of this species from specimens collected in far-eastern Russia.
His illustrations of the genitalia of both sexes fit the form of the specimens I have seen from Turkey, including the general shape of the male terminalia, with the exception that the hypoproct is not as strongly incised. His sketch of the ovipositor indicates what are presumably the ninth segment sclerites of the female. He illustrates an empodium that is somewhat longer than the claws, but this may be an artifact. Tarsal claws are often splayed, so one must be sure to find a claw that is as near as possible horizontal to determine relative length. The series of adults I have examined from Turkey shows the claws and empodia to be equally long. Following their species description of $V$. vesicula, Fedotova and Kovalev (2003) mention $J$. oenephila, not to include it in the new genus, but only to indicate that it comes from similar galls from various places in the Palearctic.

Vitisiella vesicula Fedotova \& Kovalev

Vitisiella vesicula Fedotova \& Kovalev 2003: 27.

This species from far-eastern Russia forms a circular, glabrous leaf gall, raised equally on both surfaces, but flattened, unlike the convex galls of $J$. oenephila. I have not seen specimens of this species, but the original illustrations show genitalia that are generally similar to those of $V$. brevicauda and $J$. oenephila, with a dorsally recurved aedeagus, a basally bulbous gonostylus, a deeply lobed hypoproct, and a pair of wide sclerites on the ninth segment of the ovipositor. Although the ovipositor sclerites are shown in the drawings accompanying the description of $V$. vesicula, no mention is made of them in the species description. Whether the costal vein is closed at its junction with R5 was not recorded. Fedotova and Kovalev (2003) noted and illustrated for their species a tarsal claw that is not quite as long as the empodium. 


\section{Additional Remarks}

One other described Nearctic cecidomyiid that forms galls on grape also has conspicuous sclerites on the female ninth segment but does not belong to Janetiella. This is Dasineura vitis Felt (1908: 341), a species that was originally and subsequently reared from leaf swellings purportedly similar to those made by $V$. brevicauda. Specimens of D. vitis in the Smithsonian Institution National Museum of Natural History (USNM) have been reared from blister leaf galls on grape as well, so this species may prove to be an inquiline. Dasineura vitis has toothed tarsal claws and also a broken costa at its juncture with $\mathrm{R}_{5}$. The general similarity between its ovipositor and that of Vitisiella is likely convergent, a case of different genera on a similar host sharing a similar striking character.

\section{ACKNOWLEDGMENTS}

I am grateful to the following people for their help with this research: Niklas Jönsson, Department of Entomology, Swedish Museum of Natural History, Stockholm, for the loan of specimens of Janetiella thymi; Nit Malikul, Systematic Entomology Laboratory (SEL), for preparing the slide mounts; Marie Metz, SEL, for her artful expertise in arranging the drawings onto plates; and, for their kind and helpful comments on drafts of the manuscript: Netta Dorchin, Museum Koenig, Bonn, Germany; Keith M. Harris, Woking, Surrey, United Kingdom; Allen L. Norrbom and Robert R. Kula, Systematic Entomology Laboratory. I give special thanks to David R. Smith for his careful reading of my own manuscripts during his editorship and for his many years of selfless work in ensuring the high quality of the Proceedings.

\section{Literature Cited}

Barnes, H. F. 1948. Gall Midges of Economic Importance. Vol. 3: Gall Midges of Fruit. Crosby Lockwood \& Son, London, 184 pp., 9 pls.
Coquillett, D. W. 1910. The type-species of the North American genera of Diptera. Proceedings of the United States Museum 37: 499-647.

Fedotova, Z. A., O. V. Kovalev. 2003. pp. 25-29. In Fedotova, Z. A. New genera and species of gall midges (Diptera, Cecidomyiidae) from the Russian Far East. Far Eastern Entomologist 125: 1-30.

Felt, E. P. 1908. Appendix D, pp. 286-422, 489-510, pls. 33-34. In and Felt, E. P. 1908. 23rd report of the State Entomologist on injurious and other insects of the State of New York 1907. New York State Museum Bulletin 124: 5-541, 44 pls. . 1915. Appendix: A study of gall midges III, pp. 127-288, 295-326, pls. 4-19. In 30th Report of the State Entomologist on injurious and other insects of the State of New York 1914. New York State Museum Bulletin 180: 7-336, 19 pls.

Gagné, R. J. 1968. A taxonomic revision of the genus Asteromyia (Diptera: Cecidomyiidae). Miscellaneous Publications of the Entomological Society of America 6: 1-40.

. 1981. Cecidomyiidae, pp. 257-292. In McAlpine, J. F., B. V. Peterson, G. E. Shewell, H. J. Teskey, J. R. Vockeroth, and D. M. Wood, eds. Manual of Nearctic Diptera. Vol. 1. Research Branch, Agriculture. Canada Monograph No. 27.

. 1989. The Plant-Feeding Gall Midges of North America. Cornell University Press, Ithaca, New York, xi and 356 pp. and 4 pls. 1994. The Gall Midges of the Neotropical Region. Cornell University Press, Ithaca, New York, xv \& 352 pp.

- 2004. A Catalog of the Cecidomyiidae (Diptera) of the World. Memoirs of the Entomological Society of Washington, No. 25, 408 pp.

. 2008. The Gall Midges (Diptera: Cecidomyiidae) of Hickories (Juglandaceae: Carya). Memoirs of the American Entomological Society 48: 1-147.

. 2009. The genus Arnoldiola (Diptera: Cecidomyiidae) in the Nearctic with new synonymies and combinations. Proceedings of the Entomological Society of Washington 111: 106-110.

Haimhoffen, G. R. von. 1875. Beobachtungen über die Blattgalle und deren Erzeuger auf Vitis vinifera L. Verhandlungen der kaiserlich-königlichen zoologisch-botanischen Gesellschaft in Wien 25: 803-810.

Kieffer, J.-J. 1888. Ueber Gallmücken und Mückengallen. Verhandlungen der kaiserlich-königlichen zoologisch-botanischen Gesellschaft in Wien 38: 95-114.

. 1898. Synopse des cécidomyies d'Europe et d'Algérie décrites jusqu'à ce jour. Bulletin de la Société d'Histoire Naturelle de Metz (2)8: 1-64. 
1913. Diptera. Fam. Cecidomyidae. Fasc. 152, 346 pp, 15 pls. In Wytsman, P. ed., Genera Insectorum, Bruxelles.

Kovalev, O. V. 1967. Contributions to the fauna and ecology of the gall-making insects of the Far East of the USSR, with the description of new species of Cecidomyiidae (Diptera). Akademiya Nauk SSSR, Trudy Zoologicheskogo Instituta, Leningrad 41: 80-133.

McAlpine, J. F., B. V. Peterson, G. E. Shewell, H. J. Teskey, J. R. Vockeroth, and D. M. Wood. 1981. Manual of Nearctic Diptera. Vol. 1. Research Branch, Agriculture. Canada Monograph No. 27. vi \& 674 pp.

Riley, C. V. 1873. Fifth Annual Report on the Noxious, Beneficial, and Other Insects of the State of Missouri. Jefferson City, Missouri, 160 pp.

Roskam, J. C. 1977. Biosystematics of insects living in female birch catkins. I. Gall midges of the genus Semudobia Kieffer (Diptera, Cecidomyiidae). Tijdschrift voor Entomologie 120: 153-197.
Rübsaamen, E. H. and H. Hedicke. 1938. Die Cecidomyiden (Gallmücken) und ihre Cecidien. Zoologica, (29) 77(7): 265-296, pls. XXIV-XXIX.

Skuhravá, M. 1997. Family Cecidomyiidae, pp. 71-204. In Papp, L. and B. Darvas, eds. Contributions to a Manual of Palaearctic Diptera (with Special Reference to Flies of Economic Importance). Vol 2: Nematocera and Lower Brachycera. Science Herald, Budapest.

Solinas, M. 1965. Studi sui Ditteri Cecidomiidi. I. Contarinia medicaginis Kieffer. Bollettino dell'Istituto di Entomologia della Università di Bologna 27: 249-300.

Sylvén, E. and R. Tastás-Duque. 1993. Adaptive, taxonomic, and phylogenetic aspects of female abdominal features in Oligotrophini (Diptera, Cecidomyiidae), and four new Dasineura species from the western Palearctic. Zoologica Scripta 22: 277-298. 